\title{
A Comparative Study on Effectiveness of Underpass and Overpass among Pedestrians in Different Urban Contexts in Sri Lanka
}

\author{
Dedunu Bandara, Chamali Hewawasam (i) \\ Department of Town \& Country Planning, Faculty of Architecture, University of Moratuwa, Moratuwa, Sri Lanka \\ Email: chamalih@uom.lk
}

How to cite this paper: Bandara, D., \& Hewawasam, C. (2020). A Comparative Study on Effectiveness of Underpass and Overpass among Pedestrians in Different Urban Contexts in Sri Lanka. Journal of Service Science and Management, 13, 729-744. https://doi.org/10.4236/jssm.2020.135046

Received: September 17, 2020

Accepted: October 20, 2020

Published: October 23, 2020

Copyright $\odot 2020$ by author(s) and Scientific Research Publishing Inc. This work is licensed under the Creative Commons Attribution International License (CC BY 4.0).

http://creativecommons.org/licenses/by/4.0/ (c) (i) Open Access

\begin{abstract}
The study was designed to compare and study to what extent the Underpasses and Overpasses are effective among pedestrian in different urban contexts in Sri Lanka and characteristics improve the increment of utilization of Underpasses and Overpasses. The study focuses on two Underpasses and two Overpasses. The two Underpasses are Kandy and Borella Underpasses. Panadura and Maradana are the two Overpasses. The methodology of the study comprised of On-site observations, Oral interview questionnaire survey and Semistructured interview. The data were analyzed by using frequency analysis, correlation analysis and content analysis aided by the SPSS software and MS excel. The findings on factors influencing the effectiveness of Underpass/ Overpass showed that the most influencing factor for the effective utilization of Underpass/Overpass is that the "Self-enforcement feature", while least cited factor is the "Attractiveness". In addition, the effectiveness level revealed that more effectiveness towards Underpasses than Overpasses and Underpasses suits for commercial area, Transit need areas while Overpasses suits for School/ college areas. Furthermore, the findings show that the Trip purpose and Location, Location \& Time, Trip purpose \& Time, Convenience and Comfort, Comfort and Personal safety have strong positive relationship on each other contributes for the effectiveness of the Underpass/Overpass. The study suggests that use or non-use of Overpass/Underpass is depending on attitude and behavioral pattern of pedestrians. Moreover, the study provides recommendations on towards enhancing maximum utilization. Accordingly, the results of the study provide a basis for planners, architects, developers and policy makers for the future design of effective Underpass/Overpass.
\end{abstract}

\section{Keywords}

Effective Utilization, Crossing Facility, Underpass, Overpass 


\section{Introduction}

Cities are the engine of growth. Cities have focused on pedestrian infrastructure and increase the effort on rehabilitating the cities for pedestrians. Therefore the pedestrian infrastructure is proposed for the betterment of pedestrians. Underpass/Overpass is considered as pedestrian structures and cornerstone among crossing facilities which facilitate safe in terms of vehicle-pedestrian collision. An Overpass is a vertical separation crossing facility used to separate vehicle and pedestrians and Underpass looks like a tunnel built under the motorized traffic on road (Sharples \& Fletcher, 2001).

Pedestrians tend to choose the quickest way to reach the destination without considering their safety. There were studies discussed about the factors which decide the effective utilization of Underpass/Overpass. A study of preference of pedestrians in using overpass, at-grade or underpass facility (Saha, Tishi, Islam, \& Mitra, 2013) identified that Overpass is highly preferable due to the safety and the security. Another study identifies that the insufficient security, time, poor entrance, presence of hawkers results to use underpass rather than using Overpass (Pasha, Rifaat, Hasnat, \& Rahman, 2015). Still, there is a lack of shifting the effectiveness of the Underpass and Overpass to a higher level which means that degree of success in terms of utilization and the factors directed towards the degree of success. Therefore the gap needs to be researched (Rasanen, Lajunen, Alticafarbay, \& Aydin, 2007).

In the Sri Lankan context, Overpasses and Underpasses have a great potential on reducing the pedestrian conflicts. However, pedestrian Overpasses and Underpasses are not implemented at a level to provide optimum facilities for pedestrians. Overpasses are highly agglomerated in the city of Colombo due to high pedestrian and traffic flow. Underpasses can be seen in few cities. However, pedestrians are reluctant and ignored the use of these structures. They ignore the danger and cross at grade-level crossing. The responsible authorities provide these facilities to aid pedestrian mobility. However, do not achieve the desired function and is detrimental to the authorities who provide those facilities. So, what is the effectiveness of Underpasses and Overpasses in terms of utilization which directed towards the fulfillment of needs of the pedestrians is a blooming issue in Sri Lanka.

The research questions are to compare and study to what extent the underpasses and overpasses are effective among pedestrians in different urban contexts in Sri Lanka and what characteristics should be improved to increase the utilization of underpasses and overpasses among pedestrian different urban contexts. The research questions are addresses using the main objective of to compare and assess how contributing factors influence to achieve the effectiveness of Overpasses and underpasses among pedestrians in different urban contexts in Sri Lanka and the sub objectives of to understand the level of effectiveness \& satisfaction level of underpasses and overpasses in different urban contexts, to identify the relationship between the contributing factors for the effec- 
tiveness of overpasses and underpasses, to provide recommendations based on experts' view for the future design of overpasses and underpasses to foster the effective utilization among pedestrians.

\section{Literature Review and Theories/Concepts}

There are some previous studies related and similar to the effective utilization of Underpasses and Overpasses in different contexts. A study of preference of pedestrians in using overpass, at-grade or underpass facility (Saha, Tishi, Islam, \& Mitra, 2013) identified that Overpass is highly preferable due to the safety and the security. It has been used expert opinion survey and AHP (Analytical Hierarchy Process) as analytical tools. Another study of the Evaluation of pedestrian bridges and pedestrian safety in Jordan (Abojaradeh, 2013) identifies that the bridges are safer than the tunnels. It developed a regression prediction model and found pedestrians prefer to use underpass due to the issues of discomfort, waste of time, and high stairs in the overpass.

A study carried out in Turkey (Rasanen, Lajunen, Alticafarbay, \& Aydin, 2007) based on five different kinds of Overpass on the two one way main streets of $\mathrm{CBD}$ of Ankara investigated the use or non-use of the Overpass and it used binary logistic regression. It expressed that the use or nonuse is a habit and it is not coincidental behavior. It also provides a suggestion of increasing the usability with the provision of escalators to improve the convenience. A research of The Utilization Rates of Pedestrian Bridges in Malaysia (Rizati, Endut, \& Rohani, 2013) analyze the factors which lead to low utilizing of Overpasses and it observed that the flow direction, traffic volume, distance to the facility and presence of fences have a significant impact on the utility rate of pedestrian footbridges.

However, there are lack of researches related to the level of effectiveness of the utilization of Underpass and Overpass and contributing factors to the level of effectiveness in different urban contexts.

\subsection{Factors Affect the Effective Utilization of Pedestrian Facilities}

Figure 1 shows the hierarchy of factors that are ranked based on the importance concerning the pedestrian Overpasses/Underpasses. It identified Pedestrian safety is a significant aspect which needed to be considered in the effective utilization. The link should be maintained with the land use and the movement of people. Pedestrian travel pattern needed to be recognized in order to design the pedestrian crossing facilities. A thorough understands of the trip purpose leads to a proper design of Overpass/Underpass (Hossain, 1991). Pedestrian tend to prefer a direct option which can travel in a minimum time. The aesthatic appealing quality is another factor which includes the landscaping, decoration and design. It helps to make a "sence of a place" and create a identiy to the place (Handy, Boarnet, Ewing, \& Killingsworth, 2002).

There are different studies identified different factors on effective utilization of pedestrian crossing facilities like Pedestrians perceptions for utilization of 


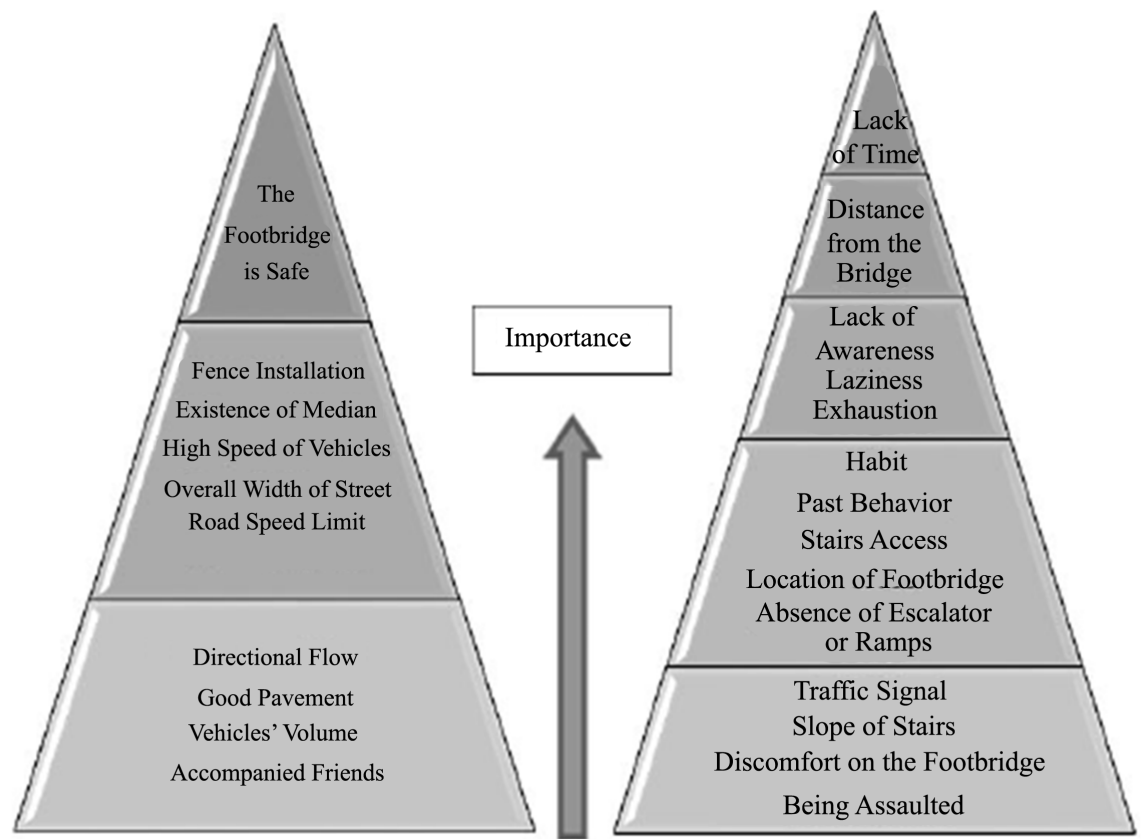

Figure 1. Hierarchy of factors influencing for use nonuse of pedestrian facilities. Source: (Hasna \& Napiah, 2017).

pedestrian facilities-Delhi, India identified factors of Convenience, safety and comfort (Rankavat \& Tiwari, 2016), a study of Urban underground space: Solving the problems of today's cities recognized Accessibility, mixed Landuse, high density, aesthetic qualities, safety, walkability as factors (Broere, 2015), Traffic volume, time, safety and aesthetic design identified in the study of A study on the effectiveness of pedestrian bridge utilization (Kadzim, 2012), A study on the efficiency of foot overpass \& underpass of Dhaka city recognized Public awareness, safety, poor entrance and distance (Rana, Hasan, \& Ahmed, 2018) and Safety, directness, beauty, amenities, comfort, purpose identified by the study of Provision \& utilization of pedestrian footbridges in cities: A case study of Mombasa road corridor Nairobi (Migo, 2018).

\subsection{Effectiveness of Underpass and Overpass Utilization}

Effectiveness means the ability to be successful and produce the intended results (without using the alternative routes, use only underpass or overpass as a crossing facility to cross the particular road that fulfills pedestrian interest by identifying pedestrian priorities). In other words, the effectiveness interprets that the degree of success of utilization by fulfilling the needs and requirements of pedestrians. In terms of pervading a safe crossing for pedestrians, still, there is a lack of shifting the effectiveness of underpasses Overpasses to a higher level. The appropriate procedures needed to be undertaken to enhance usage (Hasna \& Napiah, 2017).

Analysis of the effectiveness of the use of pedestrian bridges (Overpass) can be measured using the number of people crossing the road and the number of 
people using the Overpass (Nadjam, Ferdiansyah, \& Sitorus, 2018).

The Formula calculates the effectiveness of using pedestrian bridges $(\%)$ $=\frac{A}{B} \times 100$

$A=$ No: of pedestrian cross using the Overpass

$B=$ Total no: of pedestrian cross using the road and using the Overpass

The effectiveness derived from the formula classified into five categories as follows: (Table 1).

In the study, the effectiveness is to be applied to the Overpass as well as an Underpass to derive the effectiveness.

\subsection{Concepts Related to the Study}

\section{Pedestrian Need Concept}

The concept was first introduced by Mateo-Babiano and Leda in 2005 based on literature and introduced six pedestrian needs criteria as enjoyment, identity, protection, ease, mobility, and equitable access. It evolved as a response to create a better walking environment for the users. The development of the concept guided by pedestrian needs hierarchy by (Maslow, 1954) and pedestrian level of service which is traditionally used to design the sidewalks (Council (U.S), 2010). The pedestrian need hierarchy indicates five hierarchies. Fulfilling the needs of pedestrians leads to an increase in the satisfaction level.

A pedestrian who is walking from one place to another has certain expectations in a walking environment that contribute to the fulfillment of the needs of pedestrians. The concept expresses that pedestrian needs and requirements change according to the context. This explains certain aspects. The base-level contains the pedestrian need to move from one origin to another destination. If the pedestrian satisfied with that, the next need is to feel safe. People are using underpass and overpass to secure safety while crossing (Pasha, Rifaat, Hasnat, \& Rahman, 2015). In addition to those, certain other criteria like security, comfort, convenient walking paths make ease of walking. If the pedestrian feels ease, after that they tend to enjoy the walking experience. The highest level shows identity which means the concept of being involved with the pedestrian facility (Babiano, 2003). Ultimately, this is paving a way of satisfying the need for pedestrians.

Table 1. Level of effectiveness.

\begin{tabular}{cc}
\hline Effectiveness (\%) & Criteria \\
\hline $0-20$ & Very Ineffective \\
$21-40$ & Ineffective \\
$41-60$ & Effective enough \\
$61-80$ & Effective \\
$81-100$ & Very effective \\
\hline
\end{tabular}

Source: (Nadjam et al., 2018). 


\section{Research Methods}

\subsection{Site Selection}

Two separate Underpasses and Overpasses selected to do a comparison study. Those are selected in different urban contexts because the study is based on examining the effectiveness of different urban contexts in Sri Lanka. The transport system that exists in Colombo not meets the mobility needs of the people resulted due to random pedestrian crossings that disturb vehicles (Kalahe et al., 2017). According to the transport study in Kandy 2011, it identified the highest vehicular ownership is in the Colombo area (147 per 1000 people) while the third-highest in Kandy (61 per 1000 people) (Kandy City Transport Study, 2011). Many Overpasses are present in the city of Colombo to segregate the vehicle and pedestrian conflict. However, Underpasses cannot see in every city area. It can be seen in a few cities. Therefore I have selected Overpasses and Underpasses which are constructed in terms of fulfillment of transit needs commercial needs. The selected Overpasses are Maradana Overpass and Panadura Overpass. Borella and Kandy selected as Underpasses to carry out the study. The urban contexts selected due to these reasons. Those are located within the CBD area and on the main roads. Additionally, those are located in the busiest intersections in terms of pedestrian movement. Surrounding land uses have also taken into consideration where the areas of commercial areas and public transportation terminal areas. The selected areas have a worthy movement of both vehicles and pedestrians. The selected areas record more than 40,000 vehicular movements. Figure 2 showcase the locations of selected under passes and overpasses.

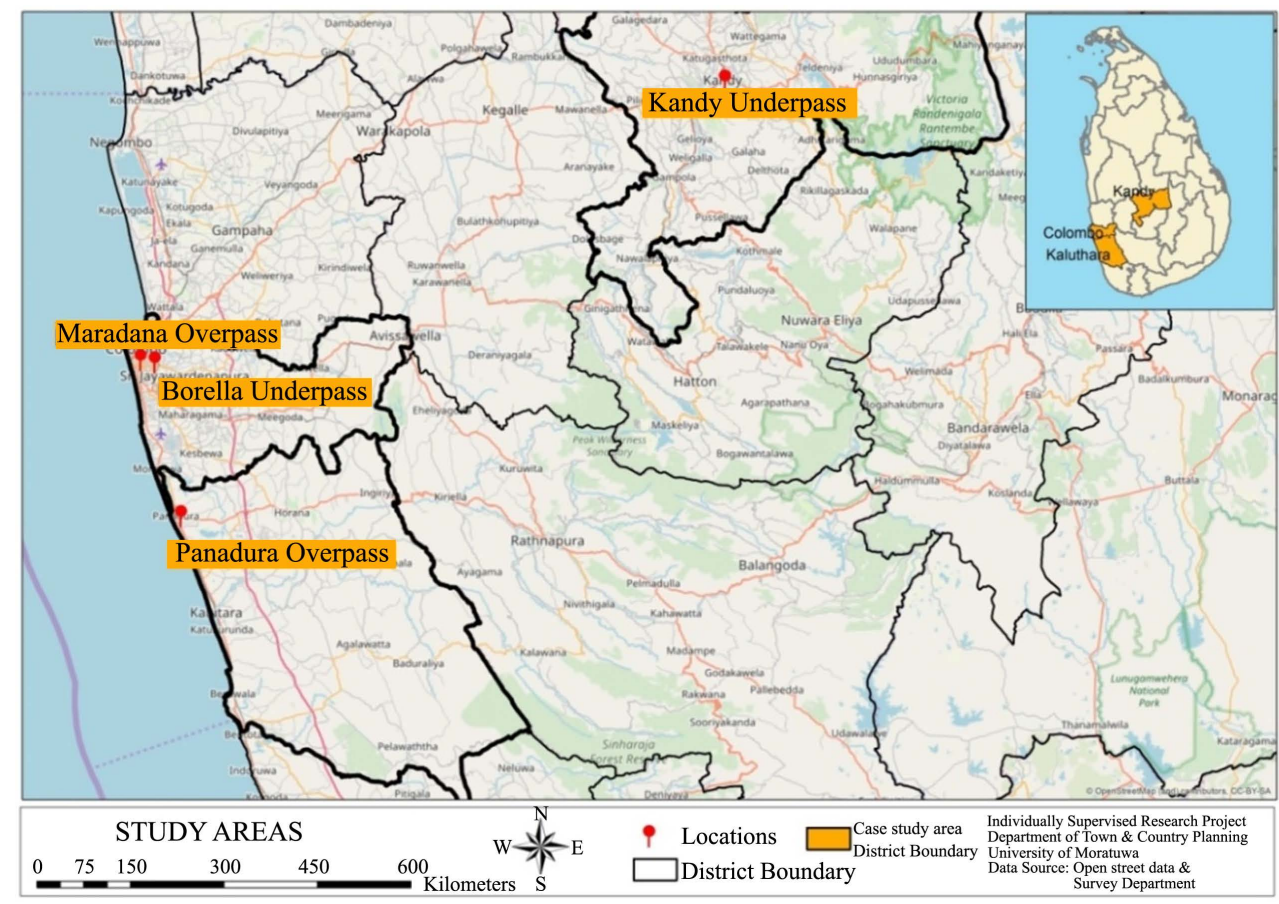

Figure 2. Location of the case studies. Source: Compiled by the author using open street maps \& survey dept. data. 


\subsection{Data Collection Methods}

\subsubsection{On-Site Observation}

In on-site observation, it identified the overview, character and the present condition of the Underpasses and Overpasses by using the photographs in selected urban contexts in Sri Lanka. In addition, it carried out a manual count to record user \& non-user volume data in peak hours to analyze the degree of effectiveness. The non-user volume data was collected as the people who cross the road in the immediate vicinity of $25 \mathrm{~m}$ from the Overpass/Underpass location. The data recorded on both weekdays and weekends at peak time intervals. In addition to that, the characteristics of pedestrians and the characteristics of Overpasses and Underpasses examined.

\subsubsection{Oral Interview Questionnaire Survey}

Questionnaire survey is used for the fulfillment of three objectives of To compare on how contributing factors influence for the effectiveness of Overpasses and Underpasses among pedestrians in different urban contexts in Sri Lanka, To understand the relationship between the identified factors for effectiveness of Overpasses and Underpasses and To understand the satisfaction level of Underpasses and Overpasses in different urban contexts. The first part of the Questionnaire survey intended to gather general information about pedestrians and the next part of the key information section gathers information related to how people satisfied with the contributing factors, what factors other than the identified factors contribute to the effectiveness etc.

\subsubsection{Semi-Structured Interview}

Experts' ideas are incorporated into the study to meet the objective to provide

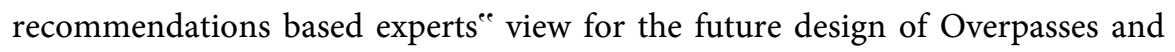
Underpasses to foster the effective utilization among pedestrians. Interviews are undertaken with open-ended questions where the natural conversation is attempted. 10 interviews are carried out with experts.

\subsection{Sample Selection}

The sampling method used in the study is the Non-Probability sampling method. It is selected mainly because the study is based on the users of the particular selected Underpasses and Overpasses. In addition to that, the mixed-method approach (qualitative \& quantitative) is used in the study. The related research studies of (Migo, 2018) have used this sampling method, as well as the method, which is selected based on the nature of the research process. In Non-probability sampling method, the convenience sampling method is selected to carry out an oral interview questionnaire survey and non-probability judgmental sampling or purposive sampling used in the qualitative study which is a semi-structured interview. The Convenience sampling method is used to identify the next pedestrian to be orally interviewed. This depicts that the approaching nth person arrived at the point where the research assistant is located to be interviewed. The 
sample size is determined as using a user count through observation which is a total of peak hour observation in a day. An average value is taken based on the observation user count and $10 \%$ of pedestrians selected from each of the underpass and overpass based on the user count. Accordingly, it was able to obtain 298 questionnaires.

\subsection{Data Analysis}

\subsubsection{Descriptive Statistical Analysis}

It is used to describe the feature of the data. It intended to find out the usage of Underpass/Overpass in different urban contexts, compare the contributing factors with the Underpass and Overpass in selected urban contexts, satisfaction level of contributing factors, degree of effectiveness of Underpass and Overpass. All the charts were prepared by using the descriptive statistical analysis by using the SPSS and MS Excel software. It can produce statistical analysis and charts, graphs.

\subsubsection{Correlation Analysis (Bivariate)}

Bivariate Correlation Analysis is a quantitative analysis used to represent the relationship between two variables. The SPPS (Statistical Package for the Social Science) used to examine the relationship between factors. Further, Pearson correlation is used because, the nominal variables used for the Correlation Analysis.

\subsubsection{Content Analysis}

Semi-structured data analyzed using the Content Analysis. Typically, this analysis helps to organize a large amount of textual data gathered in a Semi-Structured Interview into a standardized format to derive recommendations/suggestions. It collects and organizes the data into a structured format that can provide meaningful information regarding the selected aspects.

\section{Findings}

Table 2 shows the demographic characteristics of the respondents. Accordingly, the usage of Underpass and Overpass is high in the age category of $31-50$ which is $(27.2 \%)$ and 10 - 20 age category of $(24.5 \%)$ compared to other age categories. The lowest usage is among Over 61 age category of (9.7\%).In the comparison between Underpass and Overpass, Underpasses usage is high in the age category of $31-50(24.5 \%)$ and $21-30(23.3 \%)$ while in Overpasses usage is high in the age category of $31-50(30.4 \%)$ and $10-20$ age categories (29.6\%). It indicates that the Overpass usage high between youngsters than Underpasses. However, Over 61 age category use Underpass (12.9\%) more than the Overpass (5.9\%). It implies that aged people were more likely to use Underpasses. Both Underpass (54\%) and Overpass (51.1\%) usage are high between males. The females are more likely to use Underpass (47.3\%) than Overpass (46\%). More physically challenged people to use Underpass (14.1\%) than Overpass (4.4\%). However, 
Table 2. Profile of respondents.

\begin{tabular}{|c|c|c|c|c|c|c|c|}
\hline & $\begin{array}{c}\text { Total } \\
\text { sample }\end{array}$ & $\begin{array}{c}\text { Sample } \\
\text { (Only underpasses) }\end{array}$ & $\begin{array}{c}\text { Sample } \\
\text { (Only Overpasses) }\end{array}$ & $\begin{array}{c}\text { Kandy } \\
\text { Underpass }\end{array}$ & $\begin{array}{c}\text { Borella } \\
\text { Underpass }\end{array}$ & $\begin{array}{l}\text { Maradana } \\
\text { Overpass }\end{array}$ & $\begin{array}{l}\text { Panadura } \\
\text { Overpass }\end{array}$ \\
\hline \multicolumn{8}{|l|}{ Age } \\
\hline $10-20$ & $73(24.5 \%)$ & $33(20.2 \%)$ & $40(29.6 \%)$ & $8(21.05 \%)$ & $25(20 \%)$ & $30(31.3 \%)$ & $10(25.6 \%)$ \\
\hline $21-30$ & $71(23.8 \%)$ & $38(23.3 \%)$ & $33(24.4 \%)$ & $10(26.31 \%)$ & $28(22.4 \%)$ & $28(29.1 \%)$ & $5(12.8 \%)$ \\
\hline $31-50$ & $81(27.2 \%)$ & $40(24.5 \%)$ & $41(30.4 \%)$ & $9(23.7 \%)$ & $31(24.8 \%)$ & $25(26 \%)$ & $16(41 \%)$ \\
\hline $51-60$ & $44(14.8 \%)$ & $31(19 \%)$ & $13(9.6 \%)$ & $6(15.8 \%)$ & $25(20 \%)$ & $9(9.4 \%)$ & $4(10.3 \%)$ \\
\hline Over 61 & $29(9.7 \%)$ & $21(12.9 \%)$ & $8(5.9 \%)$ & $5(13.1 \%)$ & $16(12.8 \%)$ & $4(4.2 \%)$ & $4(10.3 \%)$ \\
\hline \multicolumn{8}{|l|}{ Gender } \\
\hline Male & $157(52.7 \%)$ & $88(54 \%)$ & $69(51.1 \%)$ & $25(65.8 \%)$ & $63(50.4 \%)$ & $43(44.7 \%)$ & $26(66.6 \%)$ \\
\hline Female & $147(47.3 \%)$ & $75(46 \%)$ & $66(48.9 \%)$ & $13(34.2 \%)$ & $62(49.6 \%)$ & $53(55.2 \%)$ & $13(33.3 \%)$ \\
\hline \multicolumn{8}{|l|}{ Physical Condition } \\
\hline Able Bodied & $269(90.3 \%)$ & $140(85.9 \%)$ & $129(95.6 \%)$ & $33(86.8 \%)$ & $107(85.6 \%)$ & $93(96.8 \%)$ & $36(92.3 \%)$ \\
\hline Physically challenged & $29(9.7 \%)$ & $23(14.1 \%)$ & $6(4.4 \%)$ & $5(13.1 \%)$ & $18(14.4 \%)$ & $3(3.12 \%)$ & $3(7.7 \%)$ \\
\hline \multicolumn{8}{|l|}{ Education Level } \\
\hline Not Educated & $0(0.0 \%$ & $0(0.0 \%)$ & $0(0.0 \%)$ & 0 & 0 & 0 & 0 \\
\hline Primary Level & $13(4.4 \%)$ & $6(3.7 \%)$ & $7(5.2 \%)$ & 0 & $6(4.8 \%)$ & $6(6.25 \%)$ & $1(2.56 \%)$ \\
\hline Secondary Level & $45(15.1 \%)$ & $27(3.7 \%)$ & $18(13.3 \%)$ & $3(7.9 \%)$ & $24(19.2 \%)$ & $13(13.5 \%)$ & $5(12.8 \%)$ \\
\hline Tertiary Level & $240(80.5 \%)$ & $130(79.8 \%)$ & $110(81.5 \%)$ & $35(92.1 \%)$ & $95(76 \%)$ & 77 (80.2\%) & $33(84.6 \%)$ \\
\hline Total & 298 & 163 & 135 & 38 & 125 & 96 & 39 \\
\hline
\end{tabular}

Source: Compiled by author using SPSS Software.

overall, the physically challenged people usage is low (9.7\%) compared to able-bodied people (90.3\%). All are educated up to the tertiary level in both Underpass and Overpass (80.5\%).

The level of effectiveness is obtained through an observation in selected Overpasses and Underpasses. Accordingly, the level of effectiveness indicates that in which level currently the effectiveness is positioned in Overpass/Underpass.

With reference to Table 3 the Effectiveness-8697/8945* $100=97.2 \%$

Kandy Underpass-80\% - 100\% category-Very Effective

By using Table 4 the effectiveness $-18937 / 19037{ }^{\star} 100=99.4 \%$

Borella Underpass-80\% - 100\% category-Very Effective

As indicated in Table 5 the effectiveness-3857/6379 $100=60.4 \%$

Maradana Overrpass-40\% - 60\% category-Effective enough

With reference to Table 6 the effectiveness $-4198 / 5218 * 100=80.4 \%$

Panadura Overpass-61\% - 80\% category-Effective

The findings of the observation imply that the more effectiveness $\%$ is on towards the Underpass than Overpass. However, in Overpasses, Panadura Overpass is more effective than Maradana Overpass. 
Table 3. User \& non-user volume of Kandy underpass.

\begin{tabular}{ccccccc}
\hline \multirow{2}{*}{ KANDY } & \multicolumn{2}{c}{ WEEKDAY } & \multicolumn{2}{c}{ WEEKEND } & \multicolumn{2}{c}{ Total } \\
\cline { 2 - 7 } & $\begin{array}{c}\text { Underpass } \\
\text { User }\end{array}$ & $\begin{array}{c}\text { Underpass } \\
\text { Non-user }\end{array}$ & $\begin{array}{c}\text { Underpass } \\
\text { User }\end{array}$ & $\begin{array}{c}\text { Underpass } \\
\text { Non-user }\end{array}$ & $\begin{array}{c}\text { Underpass } \\
\text { User }\end{array}$ & $\begin{array}{c}\text { Underpass } \\
\text { Non-user }\end{array}$ \\
\hline $8.30 \mathrm{am}-9.30 \mathrm{am}$ & 2156 & 30 & 1050 & 22 & 3206 & 52 \\
$12.30-1.30 \mathrm{pm}$ & 1325 & 15 & 693 & 125 & 2018 & 140 \\
$3.30-4.30 \mathrm{pm}$ & 2350 & 31 & 1123 & 25 & 3473 & 56 \\
Total & 5831 & 76 & 2866 & 172 & 8697 & 248 \\
User + Non-user & & & & & \multicolumn{2}{c}{8945} \\
\hline
\end{tabular}

Source: Compiled by author.

Table 4. User \& non-user volume of Borella underpass.

\begin{tabular}{ccccccc}
\hline \multirow{2}{*}{ BORELLA } & \multicolumn{2}{c}{ WEEKDAY } & \multicolumn{2}{c}{ WEEKEND } & \multicolumn{2}{c}{ Total } \\
\cline { 2 - 7 } & $\begin{array}{c}\text { Underpass } \\
\text { User }\end{array}$ & $\begin{array}{c}\text { Underpass } \\
\text { Non-user }\end{array}$ & $\begin{array}{c}\text { Underpass } \\
\text { User }\end{array}$ & $\begin{array}{c}\text { Underpass } \\
\text { Non-user }\end{array}$ & $\begin{array}{c}\text { Underpass } \\
\text { User }\end{array}$ & $\begin{array}{c}\text { Underpass } \\
\text { Non-user }\end{array}$ \\
\hline $8.30 \mathrm{am}-9.30 \mathrm{am}$ & 3421 & 13 & 1320 & 12 & 4741 & 25 \\
$12.30-1.30 \mathrm{pm}$ & 4220 & 12 & 1285 & 14 & 5505 & 26 \\
$3.30-4.30 \mathrm{pm}$ & 4850 & 24 & 3841 & 25 & 8691 & 49 \\
Total & 12491 & 49 & 6446 & 51 & 18937 & 100 \\
User + Non-user & & & & & \multicolumn{3}{c}{19037} \\
\hline
\end{tabular}

Source: Compiled by author.

Table 5. User \& non-user volume of Maradana overpass.

\begin{tabular}{ccccccc}
\hline \multirow{2}{*}{ MARADANA } & \multicolumn{2}{c}{ WEEKDAY } & \multicolumn{2}{c}{ WEEKEND } & \multicolumn{2}{c}{ Total } \\
\cline { 2 - 7 } & $\begin{array}{c}\text { Overpass } \\
\text { User }\end{array}$ & $\begin{array}{c}\text { Overpass } \\
\text { Non-user }\end{array}$ & $\begin{array}{c}\text { Overpass } \\
\text { User }\end{array}$ & $\begin{array}{c}\text { Overpass } \\
\text { Non-user }\end{array}$ & $\begin{array}{c}\text { Overpass } \\
\text { User }\end{array}$ & $\begin{array}{c}\text { Overpass } \\
\text { Non-user }\end{array}$ \\
\hline $8.30 \mathrm{am}-9.30 \mathrm{am}$ & 621 & 280 & 436 & 291 & 1057 & 571 \\
$12.30-1.30 \mathrm{pm}$ & 803 & 480 & 422 & 280 & 1225 & 760 \\
$3.30-4.30 \mathrm{pm}$ & 950 & 691 & 625 & 500 & 1575 & 1191 \\
Total & 2374 & 1451 & 1483 & 1071 & 3857 & 2522 \\
User + Non-user & & & & & \multicolumn{2}{c}{6379} \\
\hline
\end{tabular}

Source: Compiled by author.

Table 6. User \& non-user volume of Panadura overpass.

\begin{tabular}{ccccccc}
\hline \multirow{2}{*}{ PANADURA } & \multicolumn{2}{c}{ WEEKDAY } & \multicolumn{2}{c}{ WEEKEND } & \multicolumn{2}{c}{ Total } \\
\cline { 2 - 7 } & $\begin{array}{c}\text { Overpass } \\
\text { User }\end{array}$ & $\begin{array}{c}\text { Overpass } \\
\text { Non-user }\end{array}$ & $\begin{array}{c}\text { Overpass } \\
\text { User }\end{array}$ & $\begin{array}{c}\text { Overpass } \\
\text { Non-user }\end{array}$ & $\begin{array}{c}\text { Overpass } \\
\text { User }\end{array}$ & $\begin{array}{c}\text { Overpass } \\
\text { Non-user }\end{array}$ \\
\hline $8.30 \mathrm{am}-9.30 \mathrm{am}$ & 720 & 95 & 520 & 130 & 1240 & 225 \\
$12.30-1.30 \mathrm{pm}$ & 842 & 120 & 422 & 145 & 1284 & 265 \\
$3.30-4.30 \mathrm{pm}$ & 1020 & 250 & 654 & 280 & 1674 & 530 \\
Total & 2582 & 465 & 1616 & 555 & 4198 & 1020 \\
User + Non-user & & & & & \multicolumn{2}{c}{5218} \\
\hline
\end{tabular}

Source: Compiled by author. 
The overall satisfaction is shown in Table 7 interpret that the dissatisfaction is high towards the Overpasses of Maradana Overpass (66.6\%) and Panadura Overpass (58.9\%). In Underpasses, the overall satisfaction is very high in Kandy Underpass (60.5\%) and Borella Underpass (69.5\%). So, compared to Overpasses, the overall satisfaction is high in Underpasses than Overpasses creating a platform to understand the level of effectiveness and satisfaction of Underpasses and Overpasses.

Table 8 shows how pedestrians response to the contributing factors that those influence for the effectiveness of Underpass/Overpass. According to the responses, In Underpasses, the highest response on towards the Self-enforcement feature which is $92.1 \%$ in Kandy Underpass and $97.6 \%$ in Borella Underpass. The pedestrians' view as the reason is that the Self-enforcement features like barriers, fence installation and traffic police always enforce the pedestrians to use them insensibly. The Trip purpose has the next highest of 92.1\% in Kandy Underpass $95.2 \%$ in Borella Underpass. Other than that, more than 50\% response rate towards personal safety, Convenience, Time, Distance, Security in Underpasses. The amounts of responses are low to the factors of Attractiveness, Public awareness, and Comfort. Pedestrian stated that the absence of aesthetic appealing features, landscaping affect to reduce the Attractiveness. Comfort is reduced due to the presence of hawkers and beggars while the public awareness has a low response rate because of a lack of awareness programs to aware the public about the importance of Underpass/overpass usage.

In Overpasses, highest to the Self-enforcement features which is $88.5 \%$ in Maradana Overpass and $84.6 \%$ in Panadura Overpass while less \% of the response to the other factors. Out of 38 respondents, 12 are responded to Comfort which is $12.5 \%$ and it is the lowest in Maradana Overpass. The reason according to the pedestrians is that the presence of beggars disturbs the liberal movement of pedestrians. However, in Panadura overpass $79.5 \%$ response to the Convenience, $76.9 \%$ to the Comfort and $64.1 \%$ for Maintenance. As the reason, pedestrians mentioned that the presence of electric escalators makes them easier to use it and the presence of no hawkers and beggars creates the liberal movement of pedestrians inside the Overpass and proper maintenance by local authorities establish the maintenance inside the Overpass.

Table 7. Overall satisfaction level of underpass/overpass.

\begin{tabular}{ccccccccc}
\hline & \multicolumn{2}{c}{$\begin{array}{c}\text { Kandy } \\
\text { Underpass }\end{array}$} & \multicolumn{2}{c}{$\begin{array}{c}\text { Borella } \\
\text { Underpass }\end{array}$} & \multicolumn{2}{c}{$\begin{array}{c}\text { Maradana } \\
\text { Overpass }\end{array}$} & \multicolumn{2}{c}{$\begin{array}{c}\text { Panadura } \\
\text { Overpass }\end{array}$} \\
\cline { 2 - 9 } & Frequency & $\%$ & Frequency & $\%$ & Frequency & $\%$ & Frequency & $\%$ \\
\hline Very Satisfied & 23 & $60.5 \%$ & 47 & $37.6 \%$ & 5 & $5.2 \%$ & 5 & $12.8 \%$ \\
Satisfied & 7 & $18.4 \%$ & 10 & $8.0 \%$ & 0 & $0.0 \%$ & 0 & $0.0 \%$ \\
Neutral & 8 & $21.1 \%$ & 57 & $45.6 \%$ & 12 & $12.5 \%$ & 11 & $28.2 \%$ \\
Dissatisfied & 0 & $0.0 \%$ & 11 & $8.8 \%$ & 64 & $66.6 \%$ & 23 & $58.9 \%$ \\
Very dissatisfied & 0 & $0.0 \%$ & 0 & $0.0 \%$ & 15 & $15.6 \%$ & 0 & $0.0 \%$ \\
\hline Source: Compiled by author. & & & & & & & &
\end{tabular}


Table 8. Pedestrians' response to the contributing factors.

\begin{tabular}{|c|c|c|c|c|c|c|c|c|}
\hline & \multicolumn{8}{|c|}{ Underpass/Overpass } \\
\hline & \multicolumn{2}{|c|}{ Kandy Underpass } & \multicolumn{2}{|c|}{ Borella Underpass } & \multicolumn{2}{|c|}{ Maradana Overpass } & \multicolumn{2}{|c|}{ Panadura Overpass } \\
\hline Effectiveness (\%) & \multicolumn{2}{|c|}{ Very Effective-97.2\% } & \multicolumn{2}{|c|}{ Very Effective-99.2\% } & \multicolumn{2}{|c|}{ Effective Enough-60.4\% } & \multicolumn{2}{|c|}{ Effective- $80.4 \%$} \\
\hline Factors & Frequency & $\%$ & Frequency & $\%$ & Frequency & $\%$ & Frequency & $\%$ \\
\hline Personal Safety & 31 & $81.6 \%$ & 79 & $63.2 \%$ & 24 & $25.0 \%$ & 18 & $46.2 \%$ \\
\hline Comfort & 18 & $47.4 \%$ & 53 & $42.4 \%$ & 12 & $12.5 \%$ & 30 & $76.9 \%$ \\
\hline Convenience & 25 & $65.8 \%$ & 65 & $52.0 \%$ & 13 & $13.5 \%$ & 33 & $79.5 \%$ \\
\hline Less Time Consumption & 28 & $73.7 \%$ & 91 & $72.8 \%$ & 14 & $14.6 \%$ & 16 & $41.0 \%$ \\
\hline Minimum walking distance & 28 & $73.7 \%$ & 95 & $76.0 \%$ & 16 & $16.7 \%$ & 16 & $41.0 \%$ \\
\hline Public awareness & 18 & $47.4 \%$ & 76 & $60.8 \%$ & 17 & $17.7 \%$ & 18 & $46.2 \%$ \\
\hline Attractiveness & 14 & $36.8 \%$ & 38 & $30.4 \%$ & 12 & $12.5 \%$ & 10 & $25.6 \%$ \\
\hline Trip Purpose & 32 & $84.2 \%$ & 109 & $95.2 \%$ & 21 & $21.9 \%$ & 7 & $17.9 \%$ \\
\hline Self enforcement features & 35 & $92.1 \%$ & 122 & $97.6 \%$ & 85 & $88.5 \%$ & 31 & $84.6 \%$ \\
\hline Suitable Location & 30 & $78.9 \%$ & 116 & $87.2 \%$ & 44 & $45.8 \%$ & 16 & $41.0 \%$ \\
\hline \multicolumn{9}{|l|}{ Other factors } \\
\hline Maintainance & N/A & N/A & 119 & $92.8 \%$ & 4 & $4.2 \%$ & 25 & $64.1 \%$ \\
\hline Security & N/A & N/A & 118 & $94.4 \%$ & N/A & N/A & 11 & $28.2 \%$ \\
\hline Sanitary Facilities & & & & & N/A & N/A & N/A & N/A \\
\hline Total $(\mathrm{N})$ & \multicolumn{2}{|c|}{38} & \multicolumn{2}{|c|}{125} & \multicolumn{2}{|c|}{96} & \multicolumn{2}{|c|}{39} \\
\hline
\end{tabular}

Source: Compiled by author.

Overall, the Self-enforcement feature identified as the most influencing factor for the effectiveness of both Underpasses and Overpasses. Attractiveness identified as the factor that people are least responded with and that indicates that less attractiveness affects to reduce the effectiveness of Underpass/Overpass. In Underpasses, more than $50 \%$ response to personal safety, Convenience, time, distance, trip purpose, self-enforcement feature and suitable location while Overpasses have low consideration towards these factors.

From the findings, there were various Trip purposes which are ranging from Live, Work, Shop, Recreational, Education, Bus/Railway station and "Other" trips include hospitals \& health. On all Underpasses, the trip purpose is high towards the commercial and the transit need areas while in Overpasses, the purpose of the trips is more towards the Educational areas and transit need areas. It proves that the Underpasses are more effective for commercial areas and Overpasses to the Education areas (School, tuition areas). Both the Overpasses \& Underpasses are effective in transit need areas.

Correlation analysis (Bivariate) used to investigate the relationship between contributing factors in both Underpass/Overpass in different urban contexts. It investigated that there is a significant relationship between the factors of Trip purpose and Location, Location \& Time, Trip purpose \& Time, Convenience 
and Comfort, Comfort and Personal safety which effect for the effectiveness of the Underpass/Overpass.

According to the expert point of view, there are several views provided which are helpful to increase the utilization of Underpass/Overpass. "In future we need to create spaces not only to pass. But also a place to stay". Consequently, the statement indicates that the space used for Overpasses and Underpasses at present are using only to pass from one place to another place according to their Trip purpose. However, creating that passing space as a place to stay with sitting opportunities will be a different experience for the people in Sri Lanka. "When making an Overpass or Underpass, We must think about not only the pedestrians who are living in the city. But also the newcomers to the city" According to the statement by the senior engineer, the people who are living in the city will get in to use because of the familiarity of the city area. However, the newcomers arriving in the city area are always reluctant to use Overpass/Underpass due to several reasons. Therefore, all the pedestrians needed to be taken into consideration. "Actually, though we constructed with all the safety and comfort measures, there is a necessity of establishing a strict legal framework within the Underpasses and Overpasses to manage and maintain these structures in a pedestrian-friendly way". The establishment of the strict legal framework within the Overpass/Underpass will be able to provide a pedestrian-friendly environment. "Development must be unique to the city which is located and that must not be a collection of copies or anonymous solutions that can be seen in anywhere of the world'. Accordingly, the uniqueness of the development also is an influencing character to increase the effective utilization of both Underpass and Overpass.

The main barriers to the development of Underpass/Overpass in Sri Lanka are identified by experts as cost and fund. It is a major influence faced in developing these pedestrian infrastructures.

\section{Discussion and Conclusion}

The Underpasses and Overpasses are pedestrian infrastructures considered as crossing facilities for pedestrians. The effectiveness of the Overpasses and Underpasses are within the pedestrian. Because after the construction, the pedestrians are the ones who used those facilities. However, the effectiveness of theses pedestrian infrastructures is one of the blooming issues in Sri Lanka in terms of its effective utilization. With these considerations, the study aims to compare and asses the contributing factors influence to achieve the effectiveness of Underpasses and Overpasses in different urban contexts in Sri Lanka. It also aims to understand the degree of effectiveness and satisfaction level of Underpass/ Overpass. Further, the study intended to identify the relationship between the contributing factors for the effectiveness of these pedestrian infrastructures to provide recommendations based on experts' views to improve the future design of Overpass/Underpass. These all aimed to answer the research questions of to what extent the Underpass/Overpass are effective among pedestrians and what characteristics should be improved to increase the utilization of Underpass/ 
Overpass. Further, Oral interview questionnaire Survey, On-site observation, and Semi-structured interview are conducted during the study as data collection. Accordingly, to achieve these objectives two Overpasses of Maradana and Panadura and Underpasses of Kandy and Borella are selected to carry out the study.

The key findings can be discussed in a few aspects. The degree of effectiveness and the satisfaction level of Underpasses and Overpasses in different urban contexts identified that both Kandy and Borella Underpasses are in a "Very effective" category while Pandura Overpass is in a category of "Effective" and Maradana Overpass in "Effective enough" category. The satisfaction level explored found that the pedestrians are highly "satisfied" with the "Self-enforcement features" while highly "dissatisfied" with the "Attractiveness" in both Underpasses and Overpasses. Other than that, the satisfaction is towards the factors of Personal safety, Trip purpose, Time, Distance, Public awareness, Location is high in Underpasses compared with Overpasses. The pedestrian need concept also confirms the idea. The overall satisfaction is high in Underpasses than Overpasses. It proves that more satisfaction is towards the Underpasses than Overpasses. The comparison between the contributing factors for the effectiveness indicated that the Self-enforcement feature identified as the most influencing factor for the effectiveness of both Underpasses and Overpasses. Attractiveness identified as the factor that people are least responded with and that indicates that less Attractiveness affects to reduce the effectiveness of Underpass/Overpass. Similarly, this confirms a previous study finding that the Attractiveness is a significant element in the pedestrian environment in order to become the space a fully utilized space (Fruin, 1971). Moreover, the experts' view of the degree of consideration of contributing factors in planning, designing and construction of Overpass/Underpass confirms that the highest consideration is given to Personal safety and Time in both Overpass and Underpass. Least consideration is given to the Attractiveness, Public awareness. However, many experts' view is the effective utilization of these pedestrian infrastructures depends on the attitude and the behavioral pattern of the pedestrians.

The relationship between the contributing factors for the effectiveness identified that the Trip purpose has a strong positive relationship with the Location. This confirms the notion that a suitable Location brings pedestrians to the desired destination through the identification of the need for pedestrian movement (Sisiopiku \& Akin, 2003). The purpose of the Trip also confirms that the Underpasses are suitable for commercial areas, transit need areas while Overpasses suits for School/College areas. Further, the relationship between Location and Time indicated a significant relationship between these two factors which confirms the notion that when the facility is located in an unsuitable place from pedestrians' location causes the extra-time loss (Rizati, Ishak, \& Endut, 2013). Additionally, the study revealed a positive relationship between Trip purpose and Time. It implies that the fulfillment of the Trip purpose influence to reduce the Time taken and the absence of fulfillment of Trip purpose tend to increase the Time consumption. This result confirms the notion that spends more time at the 
Underpass/Overpass as opposed to traversing to their destinations (Migo, 2018). The factors of Convenience and Comfort elaborated a statistically significant relationship which confirms the notion that more Convenience is available in the Underpass/Overpass influence for more Comfort (Carolina, 1999). The relationship between Comfort and Personal safety confirms a strong positive relationship and that confirms the notion that when the pedestrians have Comfort there, its influence to create Personal safety (Hasna \& Napiah, 2017).

Accordingly, the study serves as a basis for the forthcoming design of these pedestrian infrastructures. Therefore, the study recommends certain aspects needed in the future design of Overpasses and Underpasses to foster effective utilization. Permanent security system, green construction materials, underground railway system planning, underground shopping mall construction, recreational places, direct routes in overpasses, aesthetic view match with the city structure, good air quality, and illuminated lighting, install anti throw screens in overpasses, lively spaces with social interaction, context-specific design, topography suits structure, electric elevators, proper signage, auxiliary spaces for sitting, visual and functional coherence, maintenance and cleanliness. As a recommendation, it is needed to pay attention to aged people and disabled people in the design of Overpasses and Underpasses.

This study is limited to selected urban contexts taken due to limited time, selected respondents were taken as a representative of all pedestrians in selected study areas, Accessibility to secondary data is limited due to poor documentation of data and Limited availability of resources \& equipment leads to neglect of some of the contributing factors taken into consideration. The future studies should refer more sample size and more case study consideration to study in-depth about this research study as well as recommend exploring effectiveness in different aspects and perspectives to clarify more about these pedestrian infrastructures.

\section{Conflicts of Interest}

The authors declare no conflicts of interest regarding the publication of this paper.

\section{References}

Abojaradeh, M. (2013). Evaluation of Pedestrian Bridges and Pedestrian Safety in Jordan. Civil and Environmental Research, 3, 66-79.

Babiano, I. M. (2003). Pedestrian Space Management as a Strategy in Achieving Sustainable Mobility. Institute for Economy and the Environment, Tokyo: Foundation for Economy and Ecology.

Council (U.S), N. R. (2010). HCM 2010: Highway Capacity Manual (5th ed.). Washington DC: Transportation Research Board.

Handy, S. L., Boarnet, M. G., Ewing, R., \& Killingsworth, R. E. (2002). How the Built Environment Affects Physical Activity Views from Urban Planning. American Journal of Preventive Medicine, 23, 64-73. https://doi.org/10.1016/S0749-3797(02)00475-0 
Hasna, R., \& Napiah, M. (2017). Utilization of Footbridges: Influential Factors and Improvement Proposals. Advances in Transportation Studies: An International Journal Section, 43, 43-60.

Hossain, M. G. (1991). Effectiveness of Pedestrian Overpasses in Metropolitan Dhaka. Dhaka: Department of Civil Engineering Bangladesh, University of Engineering \& Technology.

Kadzim, N. H. (2012). A Study on Effectiveness of Pedestrian Bridge Utilization. Pahang: University Malaysia Pahang, Civil Engineering \& Earth Resources.

Kalahe, K. P. H. S., Sirisoma, R. M. N., Jayasekara, S. M., Jayasinghe, B. S., Fernando, M. S. A., \& Ranasinghe, K. G. D. S. (2017). Improvements in Pedestrian Facilities at Maharagama to Mitigate the Traffic Congestion (pp. 1-6). Sri Lanka: General Sir John Kotelawala Defence University.

Maslow, A. H. (1954). Motivation and Personality. New York: Harper \& Row Publishers.

Migo, W. L. (2018). Provision and Utilization of Pedestrian Footbridges in Cities: A Case Study of Mombasa Road Corridor of Nairobi. Nairobi: University of Nairobi.

Nadjam, A., Ferdiansyah, M., \& Sitorus, H. J. (2018). User Effectiveness and SatisfactionCrossing of People (JPO) in the Market of the Team of Kramat Jati. Polutechnology, 17, 33-43. https://doi.org/10.32722/pt.v17i1.1091

Pasha, Md. M., Rifaat, S. M., Hasnat, A., \& Rahman, I. (2015). A Study of Pedestrian Perceptions on the Usage of Road Crossing Facilities in Dhaka City. Jurnal Teknologi (Science \& Engineering), 73, 77-83. https://doi.org/10.11113/jt.v73.4292

Rana, K. M., Hasan, \& Ahmed, S. (2018). A Study on Footpass and Underpass at Daka City. International Conference on Research and Innovation in Civil Engineering (ICRICE), 1-6.

Rankavat, S., \& Tiwari, G. (2016). Pedestrians Perceptions for Utilization of Pedestrian. Transportation Research Part F: Traffic Psychology and Behaviour, 42, 495-499. https://doi.org/10.1016/j.trf.2016.02.005

Rasanen, M., Lajunen, T., Alticafarbay, F., \& Aydin, C. (2007). Pedestrian Self-Reports of Factors Influencing the Use of Pedestrian Bridges. Accident Analysis \& Prevention, 39, 969-973. https://doi.org/10.1016/j.aap.2007.01.004

Rizati, H., Ishak, S. Z., \& Endut, I. R. (2013). The Utilization Rates of Pedestrian Bridges in Malaysia. IEEE Business Engineering and Industrial Applications Colloquium (BEIAC), Langkawi, 7-9 April 2013, 646-650. https://doi.org/10.1109/BEIAC.2013.6560210

Saha, M. K., Tishi, T. R., Islam, M. S., \& Mitra, S. K. (2013). Pedestrian Behavioral Pattern and Preferences in Different Road Crossing Systems of Dhaka City. Journal of Bangladesh Insitute of Planners, 6, 149-160.

Sharples, J. M., \& Fletcher, J. P. (2001). Pedestrian Perceptions on Road Crossing Facilities. Scotland: Scottish Executive Central Research Unit. 